\title{
When We Stop Thinking about Microbes as Cells
}

\author{
van Gestel, Jordi ; Kolter, Roberto
}

\begin{abstract}
Microbes are often thought of as individual cells. However, in their natural habitats, they typically exist in the context of other cells, be they of the same or different species. How these cells interact in space and time is key to their ecology and evolution. In this perspective, we consider the implications of this in terms of the future of microbiological research. This article is part of the special issue "Microbiology: how to bridge mechanisms and phenomenology" edited by Suckjoon Jun.
\end{abstract}

DOI: https://doi.org/10.1016/j.jmb.2019.05.004

Posted at the Zurich Open Repository and Archive, University of Zurich ZORA URL: https://doi.org/10.5167/uzh-182978

Journal Article

Accepted Version

Originally published at:

van Gestel, Jordi; Kolter, Roberto (2019). When We Stop Thinking about Microbes as Cells. Journal of Molecular Biology, 431(14):2487-2492.

DOI: https://doi.org/10.1016/j.jmb.2019.05.004 


\section{When we stop thinking about microbes as cells.}

2

3

4

5

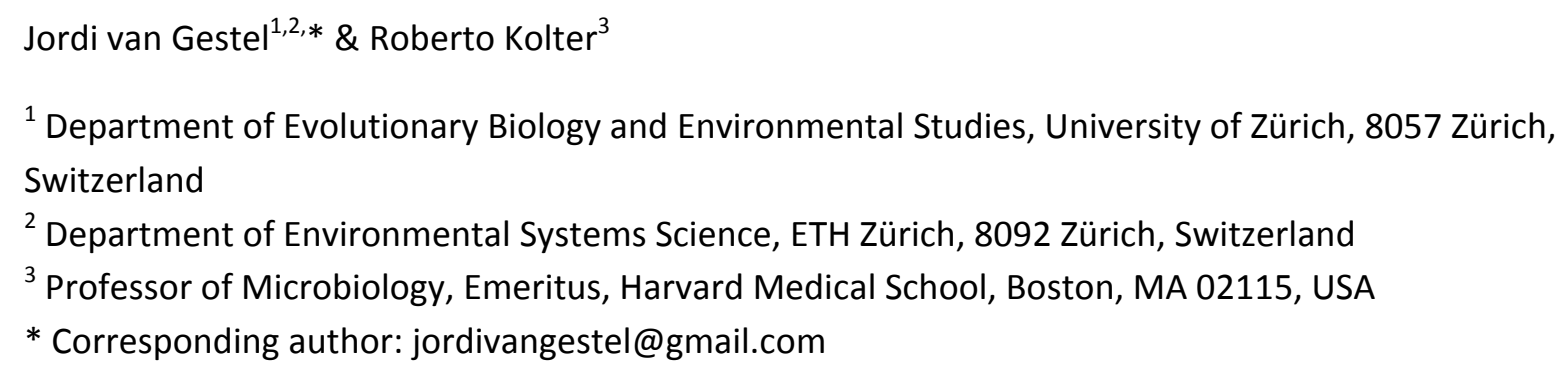

The foregoing collection of papers in this special issue on the future of microbiology make it clear that a wealth of knowledge about living systems can be learned from studying the physical properties and behaviors of microbial cells. But are microbes 'just' cells or is there more? And if there is more, what are microbes? Is there any other way we can think about microbes than cells? Here, we argue, there is. Surely, cells form the structural cornerstone of all life, including that of microbes. Yet, as soon as we try to understand what microbes do and don't do we are forced to look beyond the individual cell. We are forced to study the larger wholes of which cells are part, in both time - i.e. cell genealogies - and space - i.e. cell collectives. It is in these larger wholes where we think lies a true understanding for the remarkable capacity of microbes to deal with their environment and where much attention should be placed in the future.

One of the first to call for a drastically different view on organisms was John Tyler Bonner. In his quest to understand microscopic eukaryotic life, he postulated that not the individual, but the life cycle, is the central unit in biology (1965): "The life cycle is the central unit in biology. The notion of the organism is used in this sense, rather than that of an individual at a moment in time [...] Evolution then becomes the alternation of life cycles through time; genetics the inheritance mechanisms between cycles, and development all the changes in structure that take place during one life cycle" [1]. In other words, the developmental organization of any organism, microbes included, can only be understood in the context of its life cycle, which unfolds through the repetitive cycles of environmental change that organisms experience in nature - e.g. cycles in nutrient availability, acidity, humidity, temperature, light, competition, predation, etc.

Microbes can, for example, transition between being host-living and free-living, parasitic and mutualistic, surface-attached and dispersing, vegetative and dormant, stressed and stress free [2-8]. Most of these cycles span across generations. This means that cell genealogies undergo the phenotypic transitions that characterize the life cycle, rather than the individual cells that constitute these genealogies. These phenotypic transitions come about through the myriad of signal-response systems that enable microbes to adjust their phenotype in response to the environment. As a consequence, these signal-response systems are often tightly linked to the environmental changes that microbes experience in nature [6], making it misleading or even impossible to decouple them from their environment. For example, many signal-response systems in Escherichia coli are deemed non-essential when studying the cell cycle under the artificial conditions of the laboratory [9]. Yet, these same signal-response systems might well be of key importance for the organism's life cycle in nature. In fact, there seems to be a coarse correlation between the complexity of a microbe's life cycle in its natural setting and the number of signal response systems it contains [10,11]. For example, the bacterium Mycoplamsa genitalium, a simple obligate parasite that only survives inside its host [12], has only five one-component systems, no two-component systems, and a single sigma 
factor [13]. In contrast, Streptomyces coelicolor, a soil-dwelling microbe with an intricate multicellular life cycle [14], has 239 one-component systems, 109 two-component systems and 64 sigma factors [15]. An important challenge lies in understanding the link between signal-response systems and the life cycle transitions they mediate (e.g. [16,17]).

Importantly, microbes are not merely passive responders, laying around waiting for environmental changes to occur [18]. They often anticipate those changes [19]. E. coli, for example, prepares itself for oxidative stress when sensing higher temperatures, which is hypothesized to be an adaptation that allows $E$. coli cells to anticipate the ecological conditions of the gut upon entrance through the mouth of their mammalian host [20]. Similarly, Bacillus subtilis cells must anticipate starvation for their decision to sporulate; only by initiating sporulation on time can vegetative cells turn into spores before starving to death $[21,22]$. The decision to sporulate can even precede the actual process of sporulation by several generations [23], again pointing out that cell genealogies and not individual cells are central in understanding microbial life cycles. Recent developments combining time-lapse microscopy and microfluidics now make it possible to trace cell genealogies for extensive periods of time [24-30]. We expect that these tools will strongly aid to our understanding of microbial life cycles.

Is there anything more to cell genealogies? Yes! Microbes can not only anticipate environmental changes, they can - to a certain extend - even anticipate evolutionary changes. Many microbes have a versatile set of genome-editing mechanisms that can be induced in anticipation of natural selection, including error-prone DNA polymerases [31], phase variation through invertases [32], horizontal gene transfer through competence [33], CRISPR-Cas systems [34-36] and diversitygenerating retroelements [37,38]. Strikingly, many of these editing mechanisms target specific genes. For example, a recent study [32] on phase variation shows that these are particularly common among host-associated microbes and are often involved in regulating extracellular products important for gut colonization. By the same token, diversity-generating retroelements are found in host-associated microbes, where they predominantly affect cell attachment and defense [38]. The icing on the cake are the CRISPR-Cas systems, which function as highly-targeted adaptive immune systems that, for example, allow microbes to evade specific phage infections [39].

Genetic changes can be induced at such high frequencies that they can even form the primary mode for life cycle transitions. This is wonderfully illustrated in a recent evolution experiment of Hammerschmidt and colleagues [40], where Pseudomonas fluorescens cells were forced to alternate between free-living and surface-attached growth (specifically, growth at the liquid-air interface). Over evolutionary time, cells evolved a genetic switch - through elevated mutations rates and slipped-strand mispairing [41] - that allowed them to alternate between the different phenotypic states. The life stages associated with these phenotypic states were therefore distinct in both genotype and phenotype, akin to the alternation of generations in plants [42]. This example illustrates that recurrent genomic changes, whether or not being induced by specific environmental conditions, can be as important to a microbe's response repertoire as the recurrent regulatory changes that are induced by the signal-response systems mentioned above [43-46]. From this perspective, one could argue that any particular genotype is just a single 'instantiation' (to borrow a term from computer science) of a microbe, much like any particular phenotype is just a single instantiation of a genotype. Only by studying cell genealogies, covering many instantiations of both genotypes and phenotypes, can we understand how microbes deal with environmental change. 
Microbial signal-response systems not only span across time through cell genealogies, they can also span across space through cell collectives $[2,47]$. Although it was long thought that most microbial cells live their life in solitude, it is now clear that probably the opposite is true. Many microbes form cell collectives, ranging from the textbook examples of self-organization, like fruiting body formation in Myxococcus xanthus [48,49], to the innumerable forms of surface-associated biofilms [50,51]. In most cases, cell collectives simply emerge by cells staying together after division, but cells can also actively aggregate [52]. Inside these collectives, cells can interact through a large suite of different mechanisms. These mechanisms either lead to indirect interactions, for example through cell-to-cell communication [53,54], polysaccharide production [50,55] and metabolic cross-feeding [56], or direct interactions, through nanotubes [57-59], vesicles [60,61] and outer-membrane exchange $[62,63]$. Ultimately, cell-to-cell interactions can give rise to emergent properties that exert novel phenotypic functions $[47,64]$. For example, a few years ago we showed how $B$. subtilis cells migrate over solid surfaces by differentiating into two cell types that divide labor [65]: one cell type lubricates the surface by secreting a lipopeptide surfactant, while the other cell type forms large filamentous bundles that glide over the lubricated surface by pushing themselves away from the colony. In isolation, each of the cell types fails to migrate, but together they give rise to rapidly expanding colonies. Interestingly, Kim and colleagues [66] showed how in P. fluorescens a similar division of labor gives rise to colony expansion. Yet, in contrast to $B$. subtilis, the cell types in $P$. fluorescens colonies are genetically distinct. During colony growth, mutations rapidly arise that lead to two phenotypic variants, one of them being specialized at lubricating the surface and the other one at pushing cells away from the colony. Thus, $B$. subtilis and $P$. fluorescens cells appear to have found two alternative solutions, a regulatory switch and a genetic switch, to solve the same problem in colony expansion. Even though the solutions are not equally efficient, $B$. subtilis colonies spread much quicker than $P$. fluorescens colonies (in part because they do not have to wait for mutations to occur), this example again illustrates that recurrent genomic changes can form an essential component of a microbe's responsive repertoire.

Many cell collectives do not consist of a single species, but tens to hundreds of species $[67,68]$. These species can span across all domains of the tree of life. In recent years, there has been growing interest in studying these so-called microbiomes, in part because we now have the tools to study them (i.e. genomics, transcriptomics, metabolomics), but also because they play a pivotal role in many clinical, agricultural, and industrial settings [67-69]. In contrast to the single-species cell collectives discussed above, where developmental mechanisms control what properties emerge [7072], multi-species cell collectives are dictated by ecological interactions [73-75]. They form the ecological jungles in which microbes reside. Accordingly, they are usually referred to as microbial communities. Metagenomics has made it possible to determine the microbial composition of these communities [76-79]. Yet, in most cases, it remains unclear how these microbes interact: who kills whom, who eats whom, who competes with whom, and who cooperates with whom. Thus, in stark contrast to our molecular understanding of many individual microbes, we know surprisingly little about their ecological surroundings. Over the last decade, there has been a steady increase in the efforts to bridge this gap and study microbes in their natural habitat [80-85].

One factor that makes it challenging to study microbial communities is that they often consist of hundreds of different species, which makes it practically impossible to disentangle all their ecological interactions. To overcome this barrier, researchers are increasingly focusing on synthetic communities. These range from simple communities consisting of only two strains $[86,87]$, like 
studies on the interactions between pairs of auxotrophic $E$. coli $[58,88]$, to communities with tens of different species [89]. One promising method for selecting the species relevant to a community is by 'outsourcing' the selection procedure to nature. For example, chitin beads have been used to select marine communities from seawater [83] and Arabidopsis plants have been used to select root communities from soil samples [90]. By focusing of sets of species that are repeatedly selected from the same environment, we can simplify the community even further with the potential of characterizing all ecological interactions among the relevant members of the community. In this way, Niu and colleagues [84] selected a simplified root community of maize plants, consisting of only seven species. Since all seven species can be cultured in the lab, their ecological interactions can be studied in full detail. What chemicals do they produce? What carbon sources do they consume? How does the presence of one species affect the abundance of the others? How do they spatially interact on the plant root? When we study several of these simplified communities, we can start to address general questions about the organization and functioning of microbial communities. For example, do microbes take similar ecological roles in different communities? How much redundancy is there between the ecological roles of microbes? Are ecological networks compartmentalized? What determines the robustness of microbial communities? We feel these will be key areas to investigate in the future.

We conclude that microbes are more than cells. They are organisms. They are organisms that cope with their environment in versatile ways, often spanning far beyond the individual cell in both time and space, oblivious of the concepts that comfort us. They do this in a world that is still largely alien to us: the countless of microbial communities that dominate our planet, ourselves and everything around us. For the future of microbiology, the challenge is to stop thinking about microbes as 'just' cells and explore the emergent properties that characterize their cell genealogies and cell collectives, while - at the same time - continuing to learn about the extraordinary phenotypic properties of their individual cells. Only in this way, we believe, can we admire microbes as full-fledge organisms and unravel their remarkable capacity to adapt and interact.

\section{References}

[1] J.T. Bonner, Size and Cycle: An Essay on the Structure of Biology, Princeton University Press, 1965.

[2] M.E. Davey, G.A. O’Toole, Microbial biofilms: from ecology to molecular genetics, Microbiology and Molecular Biology Reviews. 64 (2000) 847-867. doi:10.1128/MMBR.64.4.847-867.2000.

[3] R. Kolter, E.P. Greenberg, Microbial sciences: the superficial life of microbes, Nature. 441 (2006) 300-302. doi:10.1038/441300a.

[4] M. Ackermann, B. Stecher, N.E. Freed, P. Songhet, W.D. Hardt, M. Doebeli, Self-destructive cooperation mediated by phenotypic noise, Nature. 454 (2008) 987-990. doi:10.1038/nature07067.

[5] D. McDougald, S.A. Rice, N. Barraud, P.D. Steinberg, S. Kjelleberg, Should we stay or should we go: mechanisms and ecological consequences for biofilm dispersal, Nat Rev Micro. 10 (2012) 3950. doi:10.1038/nrmicro2695.

[6] C.C. Boutte, S. Crosson, Bacterial lifestyle shapes stringent response activation, Trends Microbiol. 21 (2013) 174-180. doi:10.1016/j.tim.2013.01.002.

[7] D. Claessen, D.E. Rozen, O.P. Kuipers, L. Søgaard-Andersen, G.P. van Wezel, Bacterial solutions to multicellularity: a tale of biofilms, filaments and fruiting bodies, Nat Rev Micro. 12 (2014) 115124. doi:10.1038/nrmicro3178. 
[8] G. Oliva, T. Sahr, C. Buchrieser, The life cycle of L. pneumophila: cellular differentiation is linked to virulence and metabolism, Front Cell Infect Microbiol. 8 (2018) 3. doi:10.3389/fcimb.2018.00003.

[9] E.C.A. Goodall, A. Robinson, I.G. Johnston, S. Jabbari, K.A. Turner, A.F. Cunningham, P.A. Lund, J.A. Cole, I.R. Henderson, The essential genome of Escherichia coli K-12, MBio. 9 (2018) e0209617. doi:10.1128/mBio.02096-17.

[10] E. van Nimwegen, Scaling laws in the functional content of genomes, in: Power Laws, Scale-Free Networks and Genome Biology, Springer, Boston, MA, 2006: pp. 236-253. doi:10.1007/0-38733916-7_14.

[11] E.J. Capra, M.T. Laub, Evolution of two-component signal transduction systems, Annu Rev Microbiol. 66 (2012) 325-347. doi:10.1146/annurev-micro-092611-150039.

[12] H.C. Wiesenfeld, L.E. Manhart, Mycoplasma genitalium in women: current knowledge and research priorities for this recently emerged pathogen, J Infect Dis. 216 (2017) S389-S395. doi:10.1093/infdis/jix198.

[13] L.E. Ulrich, I.B. Zhulin, The MiST2 database: a comprehensive genomics resource on microbial signal transduction, Nucleic Acids Res. 38 (2010) D401-D407. doi:10.1093/nar/gkp940.

[14] K.F. Chater, S. Biró, K.J. Lee, T. Palmer, H. Schrempf, The complex extracellular biology of Streptomyces, FEMS Microbiol Rev. 34 (2010) 171-198. doi:10.1111/j.1574-6976.2009.00206.x.

[15] S.D. Bentley, K.F. Chater, A.M. Cerdeño-Tárraga, G.L. Challis, N.R. Thomson, K.D. James, D.E. Harris, M.A. Quail, H. Kieser, D. Harper, A. Bateman, S. Brown, G. Chandra, C.W. Chen, M. Collins, A. Cronin, A. Fraser, A. Goble, J. Hidalgo, T. Hornsby, S. Howarth, C.-H. Huang, T. Kieser, L. Larke, L. Murphy, K. Oliver, S. O'Neil, E. Rabbinowitsch, M.-A. Rajandream, K. Rutherford, S. Rutter, K. Seeger, D. Saunders, S. Sharp, R. Squares, S. Squares, K. Taylor, T. Warren, A. Wietzorrek, J. Woodward, B.G. Barrell, J. Parkhill, D.A. Hopwood, Complete genome sequence of the model actinomycete Streptomyces coelicolor A3(2), Nature. 417 (2002) 141-147. doi:10.1038/417141a.

[16] J. Jones, D.J. Studholme, C.G. Knight, G.M. Preston, Integrated bioinformatic and phenotypic analysis of RpoN-dependent traits in the plant growth-promoting bacterium Pseudomonas fluorescens SBW25, Environ Microbiol. 9 (2007) 3046-3064. doi:10.1111/j.14622920.2007.01416.x.

[17] P.B. Beauregard, Y. Chai, H. Vlamakis, R. Losick, R. Kolter, Bacillus subtilis biofilm induction by plant polysaccharides, PNAS. 110 (2013) E1621-E1630. doi:10.1073/pnas.1218984110.

[18] T.J. Perkins, P.S. Swain, Strategies for cellular decision-making, Mol Syst Biol. 5 (2009). doi:10.1038/msb.2009.83.

[19] A. Mitchell, G.H. Romano, B. Groisman, A. Yona, E. Dekel, M. Kupiec, O. Dahan, Y. Pilpel, Adaptive prediction of environmental changes by microorganisms, Nature. 460 (2009) 220-224. doi:10.1038/nature08112.

[20] I. Tagkopoulos, Y.C. Liu, S. Tavazoie, Predictive behavior within microbial genetic networks, Science. 320 (2008) 1313-1317. doi:10.1126/science.1154456.

[21] P.J. Piggot, D.W. Hilbert, Sporulation of Bacillus subtilis, Curr Opin Microbiol. 7 (2004) 579-586. doi:10.1016/j.mib.2004.10.001.

[22] D. Higgins, J. Dworkin, Recent progress in Bacillus subtilis sporulation, FEMS Microbiol Rev. 36 (2012) 131-148. doi:10.1111/j.1574-6976.2011.00310.x.

[23] J.W. Veening, E.J. Stewart, T.W. Berngruber, F. Taddei, O.P. Kuipers, L.W. Hamoen, Bet-hedging and epigenetic inheritance in bacterial cell development, Proc Natl Acad Sci USA. 105 (2008) 4393-4398. doi:10.1073/pnas.0700463105.

[24] M. Ackermann, S.C. Stearns, U. Jenal, Senescence in a bacterium with asymmetric division, Science. 300 (2003) 1920-1920. doi:10.1126/science.1083532.

[25] N.Q. Balaban, J. Merrin, R. Chait, L. Kowalik, S. Leibler, Bacterial persistence as a phenotypic switch, Science. 305 (2004) 1622-1625. doi:10.1126/science.1099390.

[26] R. Rusconi, M. Garren, R. Stocker, Microfluidics expanding the frontiers of microbial ecology, Annu Rev Biophys. 43 (2014) 65-91. doi:10.1146/annurev-biophys-051013-022916. 
[27] T.M. Norman, N.D. Lord, J. Paulsson, R. Losick, Memory and modularity in cell-fate decision making, Nature. 503 (2013) 481-486. doi:10.1038/nature12804.

[28] J.R. Russell, M.T. Cabeen, P.A. Wiggins, J. Paulsson, R. Losick, Noise in a phosphorelay drives stochastic entry into sporulation in Bacillus subtilis, EMBO J. (2017) e201796988. doi:10.15252/embj.201796988.

[29] R. Mathis, M. Ackermann, Response of single bacterial cells to stress gives rise to complex history dependence at the population level, Proc Natl Acad Sci USA. 113 (2016) 4224-4229. doi:10.1073/pnas.1511509113.

[30] L. Robert, J. Ollion, J. Robert, X. Song, I. Matic, M. Elez, Mutation dynamics and fitness effects followed in single cells, Science. 359 (2018) 1283-1286. doi:10.1126/science.aan0797.

[31] A.J. Rattray, J.N. Strathern, Error-prone DNA polymerases: when making a mistake is the only way to get ahead, Annu Rev Genet. 37 (2003) 31-66. doi:10.1146/annurev.genet.37.042203.132748.

[32] X. Jiang, A.B. Hall, T.D. Arthur, D.R. Plichta, C.T. Covington, M. Poyet, J. Crothers, P.L. Moses, A.C. Tolonen, H. Vlamakis, E.J. Alm, R.J. Xavier, Invertible promoters mediate bacterial phase variation, antibiotic resistance, and host adaptation in the gut, Science. 363 (2019) 181-187. doi:10.1126/science.aau5238.

[33] D. Dubnau, Genetic competence in Bacillus subtilis, Microbiol Rev. 55 (1991) 395-424.

[34] F.J.M. Mojica, C. Díez-Villaseñor, J. García-Martínez, E. Soria, Intervening sequences of regularly spaced prokaryotic repeats derive from foreign genetic elements, J Mol Evol. 60 (2005) 174-182. doi:10.1007/s00239-004-0046-3.

[35] F.J.M. Mojica, F. Rodriguez-Valera, The discovery of CRISPR in archaea and bacteria, FEBS J. 283 (2016) 3162-3169. doi:10.1111/febs.13766.

[36] P. Mohanraju, K.S. Makarova, B. Zetsche, F. Zhang, E.V. Koonin, J. van der Oost, Diverse evolutionary roots and mechanistic variations of the CRISPR-Cas systems, Science. 353 (2016) aad5147. doi:10.1126/science.aad5147.

[37] C. Arnold, Core concepts: how diversity-generating retroelements promote mutation and adaptation in myriad microbes, PNAS. 114 (2017) 10509-10511. doi:10.1073/pnas.1714687114.

[38] B.G. Paul, D. Burstein, C.J. Castelle, S. Handa, D. Arambula, E. Czornyj, B.C. Thomas, P. Ghosh, J.F. Miller, J.F. Banfield, D.L. Valentine, Retroelement-guided protein diversification abounds in vast lineages of Bacteria and Archaea, Nat Microbiol. 2 (2017) 17045. doi:10.1038/nmicrobiol.2017.45.

[39] R. Barrangou, C. Fremaux, H. Deveau, M. Richards, P. Boyaval, S. Moineau, D.A. Romero, P. Horvath, CRISPR provides acquired resistance against viruses in prokaryotes, Science. 315 (2007) 1709-1712. doi:10.1126/science.1138140.

[40] K. Hammerschmidt, C.J. Rose, B. Kerr, P.B. Rainey, Life cycles, fitness decoupling and the evolution of multicellularity, Nature. 515 (2014) 75-79. doi:10.1038/nature13884.

[41] E.R. Moxon, P.B. Rainey, M.A. Nowak, R.E. Lenski, Adaptive evolution of highly mutable loci in pathogenic bacteria, Curr. Biol. 4 (1994) 24-33. doi:10.1016/S0960-9822(00)00005-1.

[42] K.J. Niklas, U. Kutschera, The evolution of the land plant life cycle, New Phytologist. 185 (2010) 27-41. doi:10.1111/j.1469-8137.2009.03054.x.

[43] M. Kirschner, J. Gerhart, Evolvability, PNAS. 95 (1998) 8420-8427. doi:10.1073/pnas.95.15.8420.

[44] J. Slager, J.W. Veening, Hard-wired control of bacterial processes by chromosomal gene location, Trends Microbiol. 24 (2016) 788-800. doi:10.1016/j.tim.2016.06.003.

[45] T.D. Cuypers, J.P. Rutten, P. Hogeweg, Evolution of evolvability and phenotypic plasticity in virtual cells, BMC Evol Biol. 17 (2017) 60. doi:10.1186/s12862-017-0918-y.

[46] J.L. Payne, A. Wagner, The causes of evolvability and their evolution, Nat Rev Genet. 20 (2019) 24. doi:10.1038/s41576-018-0069-z.

[47] M. Ackermann, A functional perspective on phenotypic heterogeneity in microorganisms, Nat Rev Micro. 13 (2015) 497-508. doi:10.1038/nrmicro3491.

[48] L. Jelsbak, L. Søgaard-Andersen, Pattern formation: fruiting body morphogenesis in Myxococcus xanthus, Curr Opin Microbiol. 3 (2000) 637-642. doi:10.1016/S1369-5274(00)00153-3. 
[49] P.I. Higgs, P.L. Hartzell, C. Holkenbrink, E. Hoiczyk, Myxococcus xanthus vegetative and developmental cell heterogeneity, in: Myxobacteria: Genomics and Molecular Biology, Horizon Scientific Press, Norfolk, UK, 2014.

[50] J.W. Costerton, Z. Lewandowski, D.E. Caldwell, D.R. Korber, H.M. Lappin-Scott, Microbial biofilms, Annu Rev Microbiol. 49 (1995) 711-745. doi:10.1146/annurev.mi.49.100195.003431.

[51] H.C. Flemming, J. Wingender, U. Szewzyk, P. Steinberg, S.A. Rice, S. Kjelleberg, Biofilms: an emergent form of bacterial life, Nat Rev Micro. 14 (2016) 563-575. doi:10.1038/nrmicro.2016.94.

[52] C.E. Tarnita, C.H. Taubes, M.A. Nowak, Evolutionary construction by staying together and coming together, J Theor Biol. 320 (2013) 10-22. doi:10.1016/j.jtbi.2012.11.022.

[53] M.B. Miller, and B.L. Bassler, Quorum sensing in Bacteria, Annu Rev Microbiol. 55 (2001) 165199. doi:10.1146/annurev.micro.55.1.165.

[54] A. Eldar, Social conflict drives the evolutionary divergence of quorum sensing, Proc Natl Acad Sci USA. 108 (2011) 13635-13640. doi:10.1073/pnas.1102923108.

[55] S.S. Branda, F. Chu, D.B. Kearns, R. Losick, R. Kolter, A major protein component of the Bacillus subtilis biofilm matrix, Mol Microbiol. 59 (2006) 1229-1238. doi:10.1111/j.13652958.2005.05020.x.

[56] G. D'Souza, S. Shitut, D. Preussger, G. Yousif, S. Waschina, C. Kost, Ecology and evolution of metabolic cross-feeding interactions in bacteria, Nat Prod Rep. 35 (2018) 455-488. doi:10.1039/C8NP00009C.

[57] G.P. Dubey, S. Ben-Yehuda, Intercellular nanotubes mediate bacterial communication, Cell. 144 (2011) 590-600. doi:10.1016/j.cell.2011.01.015.

[58] S. Pande, S. Shitut, L. Freund, M. Westermann, F. Bertels, C. Colesie, I.B. Bischofs, C. Kost, Metabolic cross-feeding via intercellular nanotubes among bacteria, Nat Commun. 6 (2015) 6238. doi:10.1038/ncomms7238.

[59] G.P. Dubey, G.B. Malli Mohan, A. Dubrovsky, T. Amen, S. Tsipshtein, A. Rouvinski, A. Rosenberg, D. Kaganovich, E. Sherman, O. Medalia, S. Ben-Yehuda, Architecture and characteristics of bacterial nanotubes, Dev Cell. 36 (2016) 453-461. doi:10.1016/j.devcel.2016.01.013.

[60] A. Kulp, M.J. Kuehn, Biological functions and biogenesis of secreted bacterial outer membrane vesicles, Annu Rev Microbiol. 64 (2010) 163-184. doi:10.1146/annurev.micro.091208.073413.

[61] J.P. Remis, D. Wei, A. Gorur, M. Zemla, J. Haraga, S. Allen, H.E. Witkowska, J.W. Costerton, J.E. Berleman, M. Auer, Bacterial social networks: structure and composition of Myxococcus xanthus outer membrane vesicle chains, Environ Microbiol. 16 (2014) 598-610. doi:10.1111/14622920.12187.

[62] D.T. Pathak, X. Wei, A. Bucuvalas, D.H. Haft, D.L. Gerloff, D. Wall, Cell contact-dependent outer membrane exchange in Myxobacteria: genetic determinants and mechanism, PLoS Genet. 8 (2012) e1002626. doi:10.1371/journal.pgen.1002626.

[63] D. Wall, Molecular recognition in myxobacterial outer membrane exchange: functional, social and evolutionary implications, Mol Microbiol. (2013) 209-220. doi:10.1111/mmi.12450.

[64] J. van Gestel, H. Vlamakis, R. Kolter, Division of labor in biofilms: the ecology of cell differentiation, Microbiol Spectr. 3 (2015) MB-0002-2014. doi:10.1128/microbiolspec.MB-00022014.

[65] J. van Gestel, H. Vlamakis, R. Kolter, From cell differentiation to cell collectives: Bacillus subtilis uses division of labor to migrate, PLoS Biol. 13 (2015) e1002141. doi:10.1371/journal.pbio.1002141.

[66] W. Kim, S.B. Levy, K.R. Foster, Rapid radiation in bacteria leads to a division of labour, Nature Communications. 7 (2016) 10508. doi:10.1038/ncomms10508.

[67] M. Burmølle, T.R. Thomsen, M. Fazli, I. Dige, L. Christensen, P. Homøe, M. Tvede, B. Nyvad, T. Tolker-Nielsen, M. Givskov, C. Moser, K. Kirketerp-Møller, H.K. Johansen, N. Høiby, P. $\varnothing$. Jensen, S.J. Sørensen, T. Bjarnsholt, Biofilms in chronic infections - a matter of opportunity monospecies biofilms in multispecies infections, FEMS Immunol Med Microbiol. 59 (2010) 324336. doi:10.1111/j.1574-695X.2010.00714.x. 
[68] S. Elias, E. Banin, Multi-species biofilms: living with friendly neighbors, FEMS Microbiol Rev. 36 (2012) 990-1004. doi:10.1111/j.1574-6976.2012.00325.x.

[69] E.C. Martens, M. Neumann, M.S. Desai, Interactions of commensal and pathogenic microorganisms with the intestinal mucosal barrier, Nat Rev Micro. 16 (2018) 457. doi:10.1038/s41579-018-0036-x.

[70] L. Hall-Stoodley, P. Stoodley, Developmental regulation of microbial biofilms, Curr Opin Biotechnol. 13 (2002) 228-233. doi:10.1016/S0958-1669(02)00318-X.

[71] R.D. Monds, G.A. O'Toole, The developmental model of microbial biofilms: ten years of a paradigm up for review, Trends Microbiol. 17 (2009) 73-87. doi:10.1016/j.tim.2008.11.001.

[72] J. van Gestel, C.E. Tarnita, On the origin of biological construction, with a focus on multicellularity, Proc Natl Acad Sci USA. 114 (2017) 11018-11026. doi:10.1073/pnas.1704631114.

[73] A.E. Douglas, J.H. Werren, Holes in the hologenome: why host-microbe symbioses are not holobionts, MBio. 7 (2016) e02099-15. doi:10.1128/mBio.02099-15.

[74] E. Clarke, Levels of selection in biofilms: multispecies biofilms are not evolutionary individuals, Biol Philos. 31 (2016) 191-212. doi:10.1007/s10539-016-9517-3.

[75] K.R. Foster, J. Schluter, K.Z. Coyte, S. Rakoff-Nahoum, The evolution of the host microbiome as an ecosystem on a leash, Nature. 548 (2017) 43-51. doi:10.1038/nature23292.

[76] L. Neu, C. Bänziger, C.R. Proctor, Y. Zhang, W.T. Liu, F. Hammes, Ugly ducklings-the dark side of plastic materials in contact with potable water, NPJ Biofilms Microbiomes. 4 (2018) 7. doi:10.1038/s41522-018-0050-9.

[77] P.J. Turnbaugh, R.E. Ley, M. Hamady, C.M. Fraser-Liggett, R. Knight, J.I. Gordon, The human microbiome project, Nature. 449 (2007) 804-810. doi:10.1038/nature06244.

[78] D.S. Lundberg, S.L. Lebeis, S.H. Paredes, S. Yourstone, J. Gehring, S. Malfatti, J. Tremblay, A. Engelbrektson, V. Kunin, T.G. del Rio, R.C. Edgar, T. Eickhorst, R.E. Ley, P. Hugenholtz, S.G. Tringe, J.L. Dangl, Defining the core Arabidopsis thaliana root microbiome, Nature. 488 (2012) 86-90. doi:10.1038/nature11237.

[79] M. Bahram, F. Hildebrand, S.K. Forslund, J.L. Anderson, N.A. Soudzilovskaia, P.M. Bodegom, J. Bengtsson-Palme, S. Anslan, L.P. Coelho, H. Harend, J. Huerta-Cepas, M.H. Medema, M.R. Maltz, S. Mundra, P.A. Olsson, M. Pent, S. Põlme, S. Sunagawa, M. Ryberg, L. Tedersoo, P. Bork, Structure and function of the global topsoil microbiome, Nature. 560 (2018) 233. doi:10.1038/s41586-018-0386-6.

[80] C.D. Nadell, B.L. Bassler, A fitness trade-off between local competition and dispersal in Vibrio cholerae biofilms, Proc Natl Acad Sci USA. 108 (2011) 14181-14185. doi:10.1073/pnas.1111147108.

[81] O.X. Cordero, M.F. Polz, Explaining microbial genomic diversity in light of evolutionary ecology, Nat Rev Micro. 12 (2014) 263-273. doi:10.1038/nrmicro3218.

[82] J. Schluter, C.D. Nadell, B.L. Bassler, K.R. Foster, Adhesion as a weapon in microbial competition, ISME J. 9 (2015) 139-149. doi:10.1038/ismej.2014.174.

[83] M.S. Datta, E. Sliwerska, J. Gore, M.F. Polz, O.X. Cordero, Microbial interactions lead to rapid micro-scale successions on model marine particles, Nat Commun. 7 (2016) 11965. doi:10.1038/ncomms11965.

[84] B. Niu, J.N. Paulson, X. Zheng, R. Kolter, Simplified and representative bacterial community of maize roots, Proc Natl Acad Sci USA. 114 (2017) E2450-E2459. doi:10.1073/pnas.1616148114.

[85] K. Zhalnina, K. Zengler, D. Newman, T.R. Northen, Need for laboratory ecosystems to unravel the structures and functions of soil microbial communities mediated by chemistry, MBio. 9 (2018) e01175-18. doi:10.1128/mBio.01175-18.

[86] D. An, T. Danhorn, C. Fuqua, M.R. Parsek, Quorum sensing and motility mediate interactions between Pseudomonas aeruginosa and Agrobacterium tumefaciens in biofilm cocultures, Proc Natl Acad Sci USA. 103 (2006) 3828-3833. doi:10.1073/pnas.0511323103.

[87] S.K. Hansen, P.B. Rainey, J.A.J. Haagensen, S. Molin, Evolution of species interactions in a biofilm community, Nature. 445 (2007) 533-536. doi:10.1038/nature05514. 
[88] G. D'Souza, C. Kost, Experimental evolution of metabolic dependency in bacteria, PLoS Genet. 12 (2016) e1006364. doi:10.1371/journal.pgen.1006364.

[89] J.A. Vorholt, C. Vogel, C.I. Carlström, D.B. Müller, Establishing causality: opportunities of synthetic communities for plant microbiome research, Cell Host Microbe. 22 (2017) 142-155. doi:10.1016/j.chom.2017.07.004.

[90] S.L. Lebeis, S.H. Paredes, D.S. Lundberg, N. Breakfield, J. Gehring, M. McDonald, S. Malfatti, T.G. del Rio, C.D. Jones, S.G. Tringe, J.L. Dangl, Salicylic acid modulates colonization of the root microbiome by specific bacterial taxa, Science. 349 (2015) 860-864. doi:10.1126/science.aaa8764. 